\title{
PULSÃO DE MORTE À LUZ DA TEORIA DA VIVÊNCIA DE DOR E DA PSICOLOGIA DOS FILHOS NA HORDA PRIMITIVA
}

\section{DEATH DRIVE IN THE LIGHT OF THE THEORY OF PAIN EXPERIENCE AND THE PSYCHOLOGY OF THE SONS IN THE PRIMITIVE HORDE}

\author{
Fernanda Silveira Corrêa \\ Pós doutoranda na Unicamp e professora na Universidade Paulista. \\ fernandasilveiracorrea@gmail.com
}

\begin{abstract}
RESUMO: No artigo é feita uma análise do conceito de pulsão de morte, introduzido em Além do princípio do prazer, tendo como base sua comparação com a teoria da vivência de dor, exposta por Freud em Projeto de uma psicologia, e a psicologia dos filhos da horda primitiva (a psicologia das massas), exposta em Visão geral das neuroses de transferência. São comparadas as dualidades propostas por Freud: as teorias das vivências de satisfação e de dor, as psicologias do pai primitivo e dos filhos da horda e as pulsões de vida e de morte, e são analisados seus desdobramentos. O masoquismo, tendência relacionada ao desejo da dor e à submissão dos filhos (base dos laços sociais), é eleito a principal expressão da pulsão de morte e esta é compreendida como uma tendência do organismo a deixar-se ser invadido pelas elevadas e destruidoras quantidades do mundo externo.
\end{abstract}

PALAVRAS-CHAVE: Pulsão de morte. Vivência de dor. Psicologia das massas. Masoquismo. Hipocondria.

\begin{abstract}
The concept of death drive, introduced in Beyond the Pleasure Principle, is analyzed based on its comparison with the theory of the pain experience, discussed by Freud in Project of a psychology, and with the psychology of the sons of the primitive horde (mass psychology), discussed in Overview of transference neuroses. The dualities proposed by Freud are compared: theories of experiences of satisfaction and pain, the psychologies of the primitive father and of the sons of the horde, and the drives of life and death, and their consequences are analyzed. Masochism, a tendency related to the desire for pain and the submission of sons (a basis of social ties), is chosen as the main expression of the death drive. The latter is understood as a tendency of the organism to let itself be invaded by the high and destructive quantities from the outside world.
\end{abstract}

KEYWORDS: Death drive. Pain experience. Mass psychology. Masochism. Hypochondria.

\section{CONSIDERAÇÕES INICIAIS}

Buscarei mostrar neste artigo que o conceito de pulsão de morte, introduzido por Freud em 1920 em Além do princípio do prazer, é fruto de suas reflexões sobre a teoria da vivência de dor que fora pela primeira vez elaborada em 1895, no Projeto de uma psicologia.

Reflexões que passam pela concepção da horda primitiva (da culpa do filhos depois do parricídio e da sede de submissão ao pai/líder), pelo conceito de narcisismo (quando o Eu é tomado como objeto de outro) e transformam a tendência do aparelho 
psíquico de se proteger do mundo externo hostil em uma tendência a deixar-se ser invadido por esse mundo externo hostil. Primeiramente analisarei a existência de duas teorias presentes, desde o Projeto de uma psicologia, na obra freudiana: uma baseada nas relações com os objetos de satisfação e outra nas relações com objetos hostis. Analisarei os desdobramentos de ambas as teorias na obra freudiana, para então mostrar como, em Além do princípio do prazer, há um deslocamento do núcleo do eu (e de seu trabalho de ligação) do circuito da satisfação (da relação com os objetos de satisfação) para o circuito da dor (da relação com os objetos da dor). Deslocamento que possibilita a Freud, depois de restabelecer a dualidade, fazer com o circuito da dor o mesmo que fez com o circuito da satisfação: supor, em oposição a uma tendência a proteger-se da dor, um desejo da dor (assim como, com sua noção de sexualidade e repressão, supôs o desprazer em relação aos objetos de satisfação). Desejo de dor necessário para Freud fundamentar sua tese filogenética, baseada na culpa dos filhos, e a psicologia das massas, ressentidas e com sede de submissão.

\section{DUALIDADES INCONTORNÁVEIS}

Desde o primeiro texto metapsicológico de Freud, manuscrito enviado a seu amigo Fliess em 1895, o Projeto de uma psicologia, encontramos dualidades na teoria freudiana. Dualidades geralmente baseadas em fundamentos distintos, não inteiramente compatíveis entre si. No Projeto de uma psicologia duas teorias fundamentam essa dualidade: a teoria da vivência de dor e a teoria da vivência de satisfação. A não diferenciação dessas duas teorias compromete a compreensão do mecanismo do funcionamento do aparelho psíquico. Por exemplo, pouco compreenderemos o desenvolvimento do eu, as diversas fases de seu desenvolvimento propostas por Freud ${ }^{3}$, se o considerarmos fundamentado na teoria biológica da vivência de dor e não como um desdobramento da teoria da vivência de satisfação. Se a razão da memória do caminho facilitado na vivência de dor é encontrar uma imagem de movimento que faça o objeto hostil desaparecer (uma imagem de fuga), na memória da vivência de satisfação falta a imagem de movimento que satisfaz e faz o desprazer desaparecer, por isso, uma

\footnotetext{
${ }^{3}$ Em As teorias da vivência de dor e da vivência de satisfação, no Projeto de uma psicologia, identifiquei 18 fases do eu, entre elas: investimento (ocupação) desiderativo, $1^{\mathrm{a}}$ e $2^{\mathrm{a}}$ barreiras, julgamento do eu, atenção, pensamento, ação especifica, atenção independente da fome, atenção aos objetos hostis, inibição do afeto, metas intermediárias, compreensão do objeto externo indiferente, imitação, julgamento dos objetos, pensamento teórico e pensamento crítico. 
representação toma o lugar da ação (toma o lugar da

\section{FERNANDA SILVEIRA}

imagem de movimento que determinaria a ação) e a memória provoca a alucinação em vez da ação eficiente (em vez de investir a imagem de movimento que elimina o desprazer e provoca a ação, se investe a imagem do objeto que anteriormente possibilitou a satisfação, alucinando-o). A teoria da vivência de satisfação, em vez de estar baseada em princípios biológicos como a teoria da vivência de dor, tenta dar conta de um afastamento do biológico, concebe um aparelho determinado pelas suas representações antes que pelas suas necessidades biológicas.

Uma incompatibilidade entre as fundamentações aparece de forma ainda mais explícita e, nesse caso, desconcertante em Além do princípio do prazer, na fundamentação freudiana das duas pulsões primordiais: de morte e de vida. Depois de uma consistente discussão biológica que fundamenta a pulsão de morte, Freud fundamenta a pulsão de vida no mito de Platão e nos Upanixades. Fundamentação distinta que faz do dualismo algo "incontornável”, utilizando a expressão que Oswaldo Giacoia intitula seu trabalho sobre Além do princípio do prazer (GIACOIA, 2008). Assim em Além do princípio do prazer, como no Projeto ${ }^{4}$, o funcionamento do aparelho psíquico é produto da confluência de duas grandes tendências fundamentadas de formas diversas.

Essa distinção entre duas teorias também aparecerá em Visão geral da neurose de transferência ${ }^{5}$, texto também manuscrito enviado ao psicanalista e amigo Ferenczi em 1915, no qual Freud diferencia uma psicologia do pai primitivo, psicologia que em Psicologia das massas e análise do eu ganhará o nome de psicologia do indivíduo, e uma psicologia dos filhos, que em Psicologia das massas e análise do eu ganhará o nome de psicologia das massas. Nesse caso, não temos fundamentos propriamente diferentes, mas é esclarecedor que Freud, por um lado, remete a psicologia do pai primitivo à constituição da pulsão sexual, o que foi desenvolvido a partir da teoria da vivência de satisfação (do Projeto) e culminou na pulsão de vida (de Além do princípio do prazer) e, por outro lado, remete a psicologia das massas (dos filhos da horda primitiva) à constituição das forças repressivas (que garantem o laço social) e a relaciona com o objeto hostil, portanto, remete aos desdobramentos e modificações da

\footnotetext{
${ }^{4}$ Passarei a referir-me ao Projeto de uma psicologia, como Projeto.

${ }^{5}$ Übersicht der Übertragungsneurosen (1985 [1915]. O texto tem uma tradução em português editada pela editora Imago em 1987 com o título: Neuroses de transferência: uma síntese.
} 
teoria da vivência de dor. Em Totem e tabu (1913), o objeto hostil e a vivência de dor recebem novos conteúdos: o objeto hostil, causador de

\section{FERNANDA SILVEIRA}

dor é o pai primitivo, tirano e cruel, diante de quem a submissão dos filhos estabelecerá as forças repressivas. Em Visão geral das neuroses de transferência a psicologia dos filhos, por sua vez, remete às neuroses narcisistas (psicoses), o que nos direciona ao conceito de hipocondria do texto Introdução ao narcisismo (1914), que remete à sexualização da dor.

Também em Além do princípio do prazer, as formulações sobre a pulsão de morte remetem à dor, remetem diretamente à teoria do trauma, que corresponde à teoria da vivência da dor, no Projeto. Assim podemos diferenciar as duas teorias que determinam uma dualidade "incontornável" no decorrer da obra de Freud: por um lado, a teoria da vivência de satisfação (com seus desdobramentos no conceito de pulsão sexual infantil, perversa e polimorfa), a psicologia do pai primitivo (chamada de a psicologia do indivíduo em Psicologia das massas e análise do eu) e a pulsão de vida; por outro lado, a teoria da vivência de dor, a psicologia dos filhos na horda primitiva (psicologia das massas) e a pulsão de morte, que abordaremos neste artigo.

A teoria da vivência de dor - a teoria do trauma e da sedução - logo depois do Projeto foi abandonada por Freud. A repressão, explicada inicialmente pela teoria da vivência de dor (segundo Freud, como se foge do objeto que causa dor, desinvestindo sua imagem perceptiva, desinveste-se também a imagem recordativa do objeto, o que consiste na repressão), passou a fazer parte da teoria da vivência de satisfação. Se logo Freud supôs que o reprimido era um desejo em conflito com as exigências morais do Eu (e não uma vivência propriamente de dor), a repressão passou definitivamente para o lado da teoria da vivência de satisfação quando foi introduzido o conceito de sexualidade infantil, perversa e polimorfa, portanto, quando Freud supôs uma sexualidade que, no curso de seu desenvolvimento, era necessariamente submetida à repressão (às formações reativas). A teoria da vivência de satisfação, desde o Projeto, explica a alucinação, o princípio do prazer, o processo primário e seu desenvolvimento em processo secundário, este baseado na inibição da alucinação e na constituição de processos de energia ligada. A teoria da sexualidade acrescentará, à teoria da vivência de satisfação, a plasticidade da pulsão e seu afastamento, agora explicitado, das funções biológicas. A pulsão sexual satisfaz-se nos traços de memória (alucinados) constituídos nas mais diversas vivências de satisfação. De acordo com o Projeto, inibida a 
alucinação, os investimentos permanentes e simultâneos (do Eu) se expandem determinando um estado ligado, que agora, por meio do pensamento, da ligação entre as representações, compara a imagem alucinada com apercebida e transforma a realidade percebida na desejada.

No desenrolar de Além do princípio do prazer o processo de ligação, em vez de remeter ao processo de expansão de um Eu-prazer (constituído a partir dos prazeres sexuais e das representações dos objetos de satisfação, originalmente alucinadas e indiferenciadas do Eu), remeterá à defesa diante do mundo hostil e da vivência traumática (portanto, aos temas relativos à teoria da vivência de dor). A ideia de que as lembranças traumáticas devem submeter-se ao processo de ligação não está totalmente ausente no Projeto, pois, nesse texto, o Eu terá de inibir a liberação afetiva e a exagerada defesa diante da percepção e da recordação do objeto hostil, o que corresponde ao desgaste da representação afetiva.

Mas, no Projeto, o desgaste da recordação afetiva não é o núcleo do processo de ligação e sim um ganho secundário do Eu. O núcleo do processo de ligação, do Eu, no Projeto, assim como no capítulo 7 de Interpretação dos sonhos, em Formulações sobre os dois princípios do funcionamento psíquico, e aparentemente no primeiro capítulo de Além do princípio do prazer, é a vivência de satisfação e não a de dor. Em Além do Princípio do Prazer, no entanto, Freud parece deslocar o núcleo do processo de ligação da vivência de satisfação para a vivência de dor.

\section{DESDOBRAMENTOS DA TEORIA DA VIVÊNCIA DE DOR E DAS RELAÇÕES COM O OBJETO HOSTIL}

O deslocamento do núcleo do processo de ligação para a vivência de dor pareceme importante para a compreensão a posteriori daquilo que é novo na teoria da vivência de dor quando, depois de abandonada junto com a teoria do trauma, ela é retomada em Totem e tabu e em Introdução ao narcisismo. Se no Projeto havia uma defesa do aparelho, por isso seu apoio no biológico, contra a invasão de altas Quantidades em seu interior, a oposição a essa defesa (quer dizer, "não se defender") será a base do conceito de pulsão de morte. No Projeto, a função biológica de defesa fundamenta a arquitetura do aparelho e seu funcionamento que é encontrar o caminho mais rápido de eliminação da Q. Esse funcionamento determina que perante a percepção do objeto hostil, objeto que anteriormente causou dor, novamente sejam investidas as imagens de movimento de 
fuga (que fizeram anteriormente a percepção desaparecer) e com isso o organismo consiga fugir. Para que as imagens de movimento sejam investidas antes de ocorrer uma nova vivência de dor, o aparelho psíquico, suposto por Freud, libera quantidades, afetos, que possibilitam que o organismo se antecipe a uma nova vivência de dor e a evite.

O que Totem e tabu apresenta de novo na teoria da vivência de dor? Nesse texto, o pai primitivo, inimigo dos filhos, odiado pelos mesmos (o objeto hostil por excelência) é também objeto de amor e seu assassinato gera culpa. Os filhos se submetem a posteriori às ordens do terrível pai, às ordens do objeto hostil. Se os filhos se defendem do objeto hostil fugindo e o matando, também sentem culpa pelo seu assassinato, culpa que determina a própria constituição da cultura e da sociedade. Segundo Freud, o pacto dos irmãos não se baseia apenas em motivos racionais, quer dizer, no interesse do grupo dos irmãos que inibem suas pulsões para viver juntos e para ninguém tomar o lugar do pai, também se baseia em motivos emocionais, na culpa diante do parricídio. Se a ambivalência, analisada em Totem e tabu, remete à repressão do que é desejado, também remete ao amor ao inimigo, portanto, ao amor dirigido ao objeto hostil. A submissão a ele será fator determinante da constituição da sociedade e da cultura.

Na sua prática clínica, Freud também encontra a submissão, aqui identificada como um desejo: a neurose do homem dos lobos tem sua origem, como é revelado em seu sonho dos lobos, no conflito gerado pelo desejo de ser objeto sexual do pai e a condição para a realização desse desejo: a castração. Na análise da autobiografia de Schreber, realizada por Freud, também é evidenciado o desejo do juiz presidente de se tornar mulher para Deus, quer dizer, para o pai. A resistência ao objeto vai dando lugar à submissão, ao desejo de submeter-se ao outro.

O texto Introdução ao narcisismo revela uma erotização da posição de objeto, tanto do órgão sexual, como do próprio Eu. Em complemento a um narcisismo do sujeito, já antes formulado, que corresponde à sexualidade perversa e polimorfa e aos desejos satisfeitos pelas recordações/representações (onipotência do pensamento), surge um narcisismo de objeto, no qual o sujeito se satisfaz na posição de objeto de seu próprio amor ou na posição de objeto do amor do outro, como é o caso das mulheres narcisistas que querem ser amadas. A posição passiva, de objeto, também em Introdução ao narcisismo, será relacionada com a dor e com a hipocondria, como se, antes de ser objeto de si mesmo, se fosse objeto de um outro hostil (externo) que provoca dor no aparelho psíquico. Esse será o novo modelo da sexualidade. 
Em Visão geral das neuroses de transferência, Freud une todos esses elementos: o pai primitivo castra os filhos e a ferida dolorida da castração determina o autoerotismo (trata-se aqui do autoerotismo referente à posição de objeto), quer dizer, autoerotismo compreendido como o prazer na dor, o prazer na posição passiva-masoquista. Essa disposição surge antes da fuga dos filhos da horda e, como no homem dos lobos, é para se contrapor a ela que se foge. A partir dessa contraposição, por sua vez, se desenvolve o desejo pelo igual também ameaçado de castração, o amor homossexual pelo irmão, pelo igualmente ameaçado, que é a base dos laços sociais.

\section{TEORIA DA VIVÊNCIA DE SATISFAÇÃO EM ALÉM DO PRINCÍPIO DO PRAZER}

Freud inicia Além do princípio do prazer tratando de situações que, de acordo com o Projeto, remeteriam ao desenvolvimento do funcionamento psíquico baseado nas vivências de satisfação: a transformação do princípio do prazer em princípio de realidade, do processo primário no processo secundário (energia ligada). No Projeto (como também no capítulo 7 da Interpretação dos sonhos e em Formulações sobre os dois princípios do funcionamento psíquico) para haver essa transformação tem de haver a inibição da alucinação. Um processo similar é descrito em Além do princípio do prazer: por influência das pulsões de autoconservação do Eu será necessário "o adiamento da satisfação, a renúncia a várias possibilidades desta e a temporária aceitação do desprazer, num longo rodeio para chegar no prazer" (FREUD, 2010c [1920], p. 165). Freud afirma, no entanto, que não foi esse processo que o levou às suas reflexões sobre uma tendência além do princípio prazer.

Em seguida, ainda no primeiro capítulo de Além do princípio do prazer, Freud alude à repressão da sexualidade, que "transforma uma possibilidade de prazer numa fonte de desprazer" (FREUD, 2010c [1920], p. 167). Podemos afirmar que, ainda dentro da teoria da vivência de satisfação, trata-se das formações reativas (repressões) que nos Três ensaios sobre a teoria da sexualidade apontam o caminho para a sublimação ou para a realização da função biológica sexual. Em Visão geral das neuroses de transferência, a origem da pulsão sexual (que se satisfaz alucinatoriamente) coincide com a perda da função sexual biológica, devido às agruras da era glacial. Podemos supor que, de acordo com os Três ensaios existe uma tendência a resgatar a função perdida na filogênese. Tendência que possibilita que no intervalo entre a sexualidade perversa e a sexualidade genital - sexualidade genital que cumpre a função biológica, 
mas que nunca será inteiramente alcançada (nunca no humano a função sexual biológica será destituída da fantasia) - ocorra a sublimação. Trata-se de uma repressão originária que possibilita a sublimação.

Repressão também presente em Visão geral das neuroses de transferência, na terceira fase, quando o pai primevo inventa a linguagem (proporciona a separação entre inconsciente e pré-consciente), aprende a pesquisar e a dominar um pouco do mundo. Podemos então afirmar que se, com a teoria da vivência de satisfação do Projeto, Freud apenas expôs o mecanismo de inibição da alucinação, de formação do Eu, do processo secundário e do princípio da realidade, com o conceito de sexualidade infantil, perversa e polimorfa, ele fundamenta sua teoria. $\mathrm{O}$ fato do ser humano satisfazer-se com suas representações (de forma alucinatória) deve-se a perda da função biológica (em Visão geral, perda ocorrida na história da espécie). Entre essa pulsão e a reaquisição da função biológica (que jamais será realizada, mas que organiza o desenvolvimento) existe o espaço para a constituição do Eu - quer dizer, para uma organização com energia ligada, na qual ocorre o processo secundário e é regida pelo princípio da realidade portanto, o espaço para a sublimação.

Mas, assim como o adiamento da satisfação, a repressão também não aponta para algo além do princípio do prazer. Depois de apresentar, no capitulo I de Além do princípio do prazer, suas teses a respeito da pulsão sexual, Freud afirma que não é disso que tratará o texto e termina o capítulo indicando qual será o âmbito de suas próximas reflexões: "a investigação da reação psíquica ao perigo externo" que "pode fornecer novo material e novas colocações ao problema que aqui tratamos" (FREUD, 2010c [1920], p. 167). Então, nas palavras de Freud, a discussão principal de Além do princípio do prazer versará sobre as relações com o mundo externo perigoso, nos termos do Projeto, das relações do aparelho psíquico com o objeto hostil.

Podemos então afirmar que se no primeiro capítulo de Além do princípio do prazer Freud referiu-se ao que no Projeto remetia à teoria da vivência de satisfação (e seu complemento, nos Três ensaios da teoria sexual, à teoria da sexualidade infantil) e ao que em Visão geral das neuroses de transferência remetia à psicologia do pai primitivo (que separa consciente de inconsciente, inventa a linguagem e sublima), a partir do segundo capítulo, Freud referir-se-á à teoria da vivência de dor, à teoria da reação psíquica ao perigo externo.

Processo de ligação e Processo de desgaste das RePresentações AFETIVAS 
A partir do segundo capítulo de Além do princípio do prazer, Freud se foca então em casos que repetem vivências que nunca foram prazerosas, que repetem vivências de dor: sonhos que repetem situações traumáticas, nas neuroses traumáticas e de guerra; o jogo em que a criança repete a vivência de separação da mãe ou de sua ida ao médico; pacientes que repetem na transferência a vivência de seu complexo de Édipo, não o amor pela mãe, mas a interdição deste amor, e fazem de tudo para repetir com o analista a mesma interdição; e pessoas que repetem em seu destino situações dolorosas, por exemplo, o abandono de benfeitores ou a morte dos maridos. Nestes exemplos aparentemente a vivência dolorosa se repete (no sonho, no jogo, na transferência na análise ou no decorrer da vida) para ser ligada, elaborada, para a ela ser dado um sentido. Trata-se de traduzir na linguagem da psicanálise a ideia nietzschiana de que “qualquer sentido é melhor que nenhum” (NIETZSCHE, 1998 [1887], p. 149). Assim, na neurose traumática, o trauma que gerou terror é revivido para que o sujeito se defenda dele por meio da preparação para a angústia. A criança repete uma situação em que foi passiva, sendo agora ativa ou vingando-se do objeto que causou dor; o paciente, estimulado pela sugestão do analista, repete a situação, também traumática, para na análise ab-reagi-la. O indivíduo sofre o mesmo destino, podemos supor, talvez na esperança de elaborá-lo, buscando outro desfecho. A repetição parece uma exigência do Eu para integrar todas as suas vivências, neste sentido, para integrar aquelas vivências ainda não integradas. Na teoria da vivência da dor, no Projeto, Freud supõe algo parecido. Como vimos, diante de uma vivência de dor, fugimos; na repetição da mesma, é gerado um afeto que nos faz fugir novamente tanto de sua percepção como de sua recordação; posteriormente, no entanto, o Eu tentará inibir a produção de afeto (por meio de investimentos colaterais ao investimento dos neurônios chave, liberadores de afeto) e investir paulatinamente as lembranças da vivência de dor (relacionadas ao objeto hostil, causador de dor). Metapsicologicamente, ligar, tornar-se ativo, parece corresponder aos pequenos investimentos (pequenas ocupações - Besetzungen) da imagem do objeto hostil, que o Eu realiza, tendo controle sobre sua liberação afetiva e associando-a com outras imagens e representações (principalmente com as imagens de palavras, inicialmente, por exemplo, com a representação do grito, na dor, e também com as imagens relacionadas com o cessar da dor). Os caminhos colaterais (associações com outras representações) fazem com que o afeto se torne um simples sinal de indicação de perigo e não algo que inibe o pensar, pois exige a evitação do investimento da imagem do objeto hostil. Faz parte do desenvolvimento do $\mathrm{Eu}$ - que é "uma rede de 
neurônios ocupados [investidos], bem facilitados entre si” (FREUD, 1995 [1895] p. 37), "um grupo de neurônios cuja ocupação [cujo investimento] é constante" (id., p. 36) - a ampliação do processo de pensamento (deslocamento de pequenas Qs sobre representação/neurônios, investidas por uma Q constante), no qual são percorridas, investidas todas as representações, inclusive, as representações/imagens dos objetos hostis. O investimento inibido da imagem do objeto hostil é possibilitado pelo processo de desgaste da recordação afetiva, recordação frente a qual primeiramente fugimos com medo, mas que depois, aos poucos, dominamos, integramos, associando-a com outras representações do nosso $\mathrm{Eu}^{6}$.

Em Além do princípio do prazer, apesar da repetição das vivências de dor, nos casos elencados, parecer fruto do trabalho de desgaste, da inibição do afeto para incorporá-las ao Eu (e com isso garantir a ligação e o domínio do princípio do prazer), apesar da repetição aparentemente remeter a uma exigência do $\mathrm{Eu}$, Freud afirma que parece existir uma independência da repetição, uma compulsão independente da exigência de ligação.

Também, no Projeto, havia tendências anteriores ao processo de ligação do Eu: justamente os caminhos facilitados pelas vivências de satisfação e de dor, que o Eu, com sua energia ligada, buscava inibir, o primeiro remetendo ao desejo e sua satisfação alucinatória e o segundo remetendo à fuga, ao afeto e à repressão, em ambos os casos buscando-se o prazer ou a evitação do desprazer. O que é novo, em Além do princípio do prazer, é a repetição não da fuga da vivência de dor (fuga do investimento da imagem do objeto hostil), mas repetição da própria vivência de dor. Os sonhos das neuroses traumáticas repetem de forma alucinatória o próprio trauma, e não a fuga dele.

\section{AS ENIGMÁTICAS TENDÊNCIAS MASOQUISTAS DO EU}

A primeira referência de Freud aos sonhos das neuroses traumáticas, que repetem a situação traumática, no capítulo II de Além do princípio do prazer, termina com a afirmação de que, nesses sonhos, ou supomos que a tendência realizadora de

\footnotetext{
${ }^{6}$ No Projeto, no entanto, as representações patológicas não são submetidas ao processo de desgaste. Isso porque o afeto não está ligado a uma vivência de dor provinda de um objeto externo hostil, mas a um processo que ocorre no interior do próprio Eu e que o pega de surpresa, sem nenhuma reação anterior de fuga. Remetem geralmente a experiências sexuais, que pareceram inofensivas quando vividas e que só posteriormente geraram afeto de desprazer. Posteriormente, no entanto, são impossíveis de serem inibidas pelo Eu, pois não foram dele separadas anteriormente (não se fugiu delas, anteriormente, como se faz normalmente com representações das vivências de dor).
} 
desejos dos

sonhos, isto é, “a função ao sonho [...] é abalada ou desviada de seus propósitos, ou teríamos que lembrar as 'enigmáticas tendências masoquistas do Eu'” (FREUD, 2010c [1920], p. 170). Aparentemente, Freud nesse texto supõe uma nova função para os sonhos, como ele afirma no capítulo IV: o trabalho de ligação. No entanto, considero que não se trata de uma coisa ou outra, mas de uma coisa $e$ outra, em distintos níveis de análise. Se em um primeiro nível de análise, a repetição é atribuída ao trabalho de ligação (do Eu), e isso corresponde à nova função do sonho que é realizar o processo de ligação, antes de realizar os desejos, em um segundo nível da análise, o que se repete é o reprimido, no entanto, não o reprimido relacionado às vivências de satisfação, aos objetos desiderativos alucinados, mas relacionado às "enigmáticas tendências masoquistas do eu". Creio que, em Além do princípio do prazer, Freud fundamenta as tendências masoquistas do Eu, tendências que, em Visão geral das neuroses de transferência, foram consideradas a base da psicologia dos filhos: da submissão ao pai, do laço social e da constituição do ideal do Eu que condena o Eu (constituídas respectivamente nas quarta, quinta e sexta fases filogenéticas). Assim, se o processo de ligação está a serviço do processo de desgaste, para que se evite o desprazer, na verdade, ele é posterior a uma tendência que visa ao desprazer, visa à dor, por isso masoquista.

Vejamos isso mais vagarmente. Se a análise dos jogos infantis (o jogo do fort/da, a brincadeira que transforma a vivência passiva no médico em ativa, a brincadeira com a imagem de si mesmo no espelho) indica que a repetição visa ao domínio da situação anteriormente passiva, ou à vingança, a análise da transferência que ocorre no processo analítico indicará que a repetição (a transferência de um material passado para o presente) é também fruto da resistência do Eu. Resistência que impede o surgimento das recordações reprimidas, como fora descrito em 1914 em Recordar, repetir e elaborar. Em Além do princípio do prazer, Freud escreve:

O doente não pode lembrar-se de tudo o que nele está reprimido, talvez precisamente do essencial, não se convencendo da justeza da construção que lhe é informada. Ele é antes levado a repetir o reprimido como vivência atual, em vez de, como preferiria o médico, recordá-lo como parte do passado (FREUD, 2010c [1920], p. 177).

A repetição, nesse caso, ocupa o lugar da recordação, se repete para não 
recordar. A repetição, portanto, se opõe ao processo de ligação, já que este é concebido como a possibilidade de percorrer todas as representações/recordações.

A repetição, nesse caso, coincide com a resistência, que é também uma parte inconsciente do $\mathrm{Eu}$, mas que se opõe à ligação:

Os fenômenos da transferência acham-se claramente a serviço da resistência por parte do Eu, que persevera na repressão; a compulsão à repetição, de que o tratamento pretendia se valer, é como que puxada para o lado do Eu, que se apega ao princípio do prazer (FREUD, 2010c [1920], p. 183).

Assim, o Eu repete não só com o intuito de dominar (apoderar-se de todas suas recordações, ligar), ele também repete por causas opostas, quer dizer, para evitar que algumas recordações venham à consciência, para mantê-las reprimidas. É importante ressaltar que a tarefa de ligação do $\mathrm{Eu}$ (o desenvolvimento do processo secundário) é posterior a tarefa da repressão. No Projeto, Freud supôs, no caminho primário facilitado pela vivência de dor, uma repressão primária que ocorria em $\psi$, e que correspondia a um mecanismo de defesa do organismo de afastar a percepção e a recordação do objeto hostil. A repressão primária era independente do $\mathrm{Eu}$ e o Eu tinha como tarefa, como vimos anteriormente, desgastar a representação afetiva: inibir a liberação afetiva e investir (ocupar) a representação antes reprimida, quer dizer ligá-la com suas outras representações para avaliar o perigo e fugir apenas quando necessário. Por considerar a repressão primária fruto do funcionamento de $\psi$, portanto, independente do $\mathrm{Eu}$, no Projeto, Freud não precisou supor distintas tarefas do Eu, no que diz respeito ao caminho facilitado pela vivência de dor. Mas quando a repressão passou a ser suposta ocorrendo sobre os objetos de satisfação (quando elaborado o conceito de sexualidade infantil), o Eu passou a ter uma dupla tarefa: reprimir (afastar) e ligar (unir, como atesta o processo secundário). O Eu então passou a ser constituído não apenas pelos caminhos facilitados pelas vivências de satisfação (Eu-prazer) e os caminhos colaterais a esses primeiros caminhos, como fôra suposto no Projeto, mas também pelas formações reativas, responsáveis pela repressão, que se contrapõem satisfações sexuais ${ }^{7}$.

Se a resistência, que visa a manutenção da repressão, se repete (e aqui novamente

\footnotetext{
${ }^{7}$ No Projeto, o trabalho realizado pelo Eu de inibição do caminho facilitado pela vivência de satisfação, por sua vez, não consiste em uma repressão, pois a representação do objeto desiderativo continua sendo investida (ocupada). Seu investimento é apenas atenuado, inibido, para que não ocorra a alucinação, mas permaneça sendo a meta do pensamento, quer dizer, continue atraindo as quantidades provindas da percepção, para que, se houver uma imagem de movimento entre a imagem percebida e a desejada, a primeira se transforme na segunda (por exemplo, a percepção do seio lateral, com um movimento da cabeça, se transforme no seio frontal desejado).
} 
a repetição coincide com um trabalho do Eu), ela ocorre porque antes dela a pressão do reprimido se repete. A resistência se repete para manter a repressão sobre um material que insiste em se repetir,

a resistência do analisando vem de seu $\mathrm{Eu}$, e logo percebemos que a compulsão a repetição deve ser atribuída ao reprimido inconsciente. Ela não podia manifestar-se até que o trabalho terapêutico, vindo-lhe ao encontro, afrouxou a repressão (FREUD, 2010c [1920], p. 178/9).

Mas o que é o reprimido? Freud afirma que grande parte desse material reprimido, como já foi abordado no primeiro capítulo, remete às vivências de satisfação:

a maior parte do que a compulsão de repetição faz reviver causa necessariamente desprazer ao Eu, pois traz à luz atividades de impulsos pulsionais reprimidos, mas é um desprazer que já consideramos, que não contraria o princípio do prazer, é desprazer para um sistema e, ao mesmo tempo, satisfação para o outro (FREUD, 2010c [1920], p. 179).

No entanto há algo novo, quer dizer, há uma nova interpretação do material que se repete: "Mas o fato novo e digno de nota, que agora temos que descrever, é que a compulsão à repetição também traz de volta experiências do passado que não possibilitam prazer, que também naquele tempo não podem ter sido satisfações" (FREUD, 2010c [1920], p. 179). Trata-se de uma interpretação nova, pois até então Freud considerava que a repetição de uma situação desprazerosa trazia em si um prazer proibido, como o próprio Freud nos lembra, mais adiante, no próprio Além do princípio do prazer, a respeito dos pesadelos: "os sonhos de castigo substituem a realização proibida do desejo pelo castigo que lhe é apropriado" (FREUD, 2010c [1920], p. 196). Também os sintomas (e a transferência entre eles) sempre foram compreendidos como formações de compromisso, quer dizer, ao mesmo tempo que satisfaziam o impulso insatisfeito, na fantasia, satisfaziam também as forças repressivas (punitivas), produzindo sofrimento. Neste sentido, repetir na análise a circunstância penosa da perda do amor da mãe, significava satisfazer esse amor, na fantasia, por meio da punição por realizá-lo. Agora a interpretação é outra: há um impulso a repetir uma vivência que nunca causou prazer, ao contrário, causou dor, sofrimento. O núcleo do reprimido desloca-se de uma vivência de satisfação para uma vivência de dor. Algo que parece remeter às tendências masoquistas do Eu.

Devemos lembrar que pouco antes da publicação de Além do princípio do prazer, Freud havia publicado, em 1919, o texto Batem em uma criança, no qual analisou fantasias nas quais crianças são surradas e que, tanto nas meninas como nos 
meninos, remetem a uma fase inconsciente na qual a própria criança é surrada pelo pai, uma fantasia masoquista que no caso dos meninos corresponde a atitude edípica inversa à atitude normal, remete a uma fantasia feminina do menino de ser amado pelo pai. Também em Visão geral das neuroses de transferência, como vimos, o masoquismo parece coincidir com o autoerotismo que surge na primeira fase da psicologia dos filhos. Freud supôs que, na história filogenética, a castração, que o pai primitivo infligia a seus filhos, determinou o autoerotismo, que é a disposição para a demência precoce. A autocastração na demência precoce expressa essa disposição. Também, como já vimos, Freud em Introdução ao narcisismo relacionou as neuroses narcisistas à dor e à hipocondria (esta seria para as neuroses narcisistas o que a angústia é para a neurose de transferência) e, tanto no caso Schreber como no Homem dos Lobos, vinculou o desejo de se tornar mulher para o pai à castração. A disposição para a demência precoce, que remete à hipocondria, parece, portanto, corresponder à sexualização da dor, ao desejo masoquista de dor e de submissão ao pai. Aí surge, portanto, a dimensão do narcisismo no qual o Eu é tomado como objeto de amor, primeiro do pai e depois de si mesmo, disposição que é a base dos laços sociais e fundamental para a compreensão das forças repressoras. A vida social exige a submissão ao líder, a obediência adiada, já identificada em Totem e tabu, exige também a submissão às regras sociais que implicam no repúdio de parte de si mesmo, quer dizer, implicam na repressão das próprias pulsões (culpa). Podemos então dizer que se, por um lado, as tendências masoquistas do Eu são enigmáticas, por outro, no mito da constituição da vida cultural e social (nas concepções filogenéticas), elas são o seu fundamento. Além do princípio do prazer parece, por sua vez, fornecer a elas sua base pulsional.

\section{A PROTEÇÃO VERSUS A SUBMISSÃO E A FERIDA DOLORIDA}

No capítulo IV de Além do princípio do prazer é apresentado um esquema similar ao do Projeto. Freud supõe um organismo vivo para o qual "a proteção contra estímulos é tarefa quase mais importante do que a recepção de estímulos" (FREUD, 2010c [1920], p. 189). Como no Projeto, a arquitetura do aparelho tem a função de afastar os estímulos, existe uma membrana protetora que funciona como uma barreira contra os estímulos externos. A proteção serve para preservar uma reserva própria de energia, preservar as formas especiais de transformação da energia diante da influência niveladora e, portanto, destruidora, das imensas energias que operam do lado de fora. 
Depois da barreira protetora, o estímulo, em pequenas porções, é recebido. No Projeto, é recebido para que mais rapidamente as imagens perceptivas se tornem imagens desiderativas (mesmo o pensamento teórico visa em última instância a satisfação do desejo) ou para que se reconheça o perigo real, inibindo o perigo imaginado (que determina a fuga automática). Em Além do princípio do prazer, os estímulos devem ser recebidos para ser reconhecidos, dominados. O trauma físico significa, em ambos os textos, que a barreira contra os estímulos foi rompida. No aparelho psíquico do Projeto, quando a barreira é rompida e provoca a dor, é facilitado um caminho que encontra uma imagem de movimento de fuga e o organismo foge do objeto hostil (o objeto desaparece da percepção). Em Além do princípio do prazer - assim como no Rascunho G, texto escrito em 1894 e enviado a Fliess, portanto, contemporâneo ao Projeto -, Freud concebe outra forma de proteção. De todos os lados é convocada energia de investimento, a fim de criar, em torno do lugar da irrupção, investimentos de energia correspondentemente elevados. Produz-se um enorme contrainvestimento que pode ligar a excitação vinculada à dor/terror do trauma e até aumentar seu nível de energia ligada com a excitação da própria dor. Neste caso, o núcleo do processo de ligação (processo secundário, de energia ligada, núcleo do Eu) passa a ser a vivência de irrupção das quantidades externas no interior do aparelho. Como se o Eu surgisse para dominar essas altas energias que invadem o aparelho. O processo de ligação deixa de ser um processo de atenuação do desejo, como é no Projeto, para então ser concebido como um processo de proteção, por isso, original. O núcleo do Eu (do processo de ligação) desloca-se então da vivência de satisfação para a vivência de dor, ele surge para proteger o aparelho dos destruidores estímulos do mundo externo.

O que revelam as neuroses traumáticas em Além do princípio do prazer? Nelas, Freud já havia dito no capítulo II, se corre perigo sem se estar preparado, por isso o sentimento de terror, de surpresa (Schrek). Há uma ruptura da proteção contra estímulos, não só da membrana protetora, mas também do estado de ligação, do sobreinvestimento. Se houvesse a preparação, o sobreinvestimento, haveria a proteção. E aqui Freud supõe então a outra função do sonho que não a realização alucinatória do desejo: trata-se de "lidar retrospectivamente com o estímulo, mediante o desenvolvimento da angústia" (FREUD, 2010c [1920], p. 195), "tais sonhos [...] obedecem à compulsão de repetição, no interesse do ligamento psíquico de impressões traumáticas" (id., 196/7). Trata-se de uma função que "sem contrariar o princípio do prazer, é independente dele e parece mais primitiva que a intenção de obter prazer e 
evitar desprazer" (id., p. 196). Os sonhos dos neuróticos traumáticos: “obedecem antes à compulsão de repetição, que na análise, de fato, é favorecida pelo desejo (encorajado pela 'sugestão') de evocar o que foi esquecido e reprimido" (ibidem). No caso da análise trata-se, portanto, de um movimento para romper a resistência que mantém a recordação reprimida e que é encorajado pelo analista. Trata-se então de um impulso reprimido que "deseja” a ligação (no interesse do ligamento psíquico), em oposição à repressão, que o afasta das outras representações. Voltamos à mesma questão, qual é o conteúdo reprimido que se repete, e o que Além do princípio do prazer traz de novo a seu respeito? Em primeiro lugar, apesar de presente no trauma, o que se repete é sexual. Assim Freud analisa as "neuroses de guerra": "a violência mecânica do trauma liberaria o quantum de excitação sexual que, devido à falta de preparação para a angústia, tem efeito traumático" (id., p. 197). O terror, portanto, coincide com uma excitação sexual que aparentemente rompe a barreira protetora. Poderíamos pensar que, se se trata de excitação sexual, envolve então prazer e que se, nos sonhos, é repetido o trauma, isso ocorre porque neles se realiza um desejo sexual. Mas aqui não teríamos nada de novo (nos Três ensaios sobre a teoria da sexualidade Freud já havia apontado o prazer derivado das surras recebidas) e não parece ser esse o raciocínio de Freud. No sonho traumático, em vez de haver satisfação da excitação sexual, o aparelho protege-se dela. Que excitação sexual seria essa? Em Psicologia das massas e análise do Eu, ao analisar a organização do Exército, Freud afirma: "a negligência do fator emocional no Exército (...) parece (...) um perigo prático" (FREUD, 2011 [1921], p. 48). Trata-se de um perigo prático porque causa neurose em seus soldados, já que um dos maiores motivos das neuroses de guerra foi "o tratamento sem amor que o homem comum recebia dos superiores" (id., p. 49). O que seria levar o fator emocional em conta? Considerar que "o general é o pai, que ama igualmente todos os seus soldados, e que por isso eles são camaradas entre si." (id., p. 48). Mas que tipo de amor é esse que pode ser dado pelo general? Jones faz um esclarecimento interessante sobre a compreensão de Freud e dos psicanalistas das neuroses de guerra:

era fácil atribuir, pelo menos às causas imediatas das neuroses de guerra, aos conflitos entre o instinto de autoconservação, necessidade de fugir dos perigos militares, e os vários fatores que não permitiriam a plena confissão deste fato, o sentido de dever, o treinamento com a finalidade de obediência, e assim por diante (JONES, 1979, p. 588). 
caso, era a obediência, o dever (à pátria, ao Exército, ao general), nas palavras de Freud, em Psicologia das massas e análise do Eu, a "sede de submissão" (FREUD, 2011 [1921], p. 91). Assim, a excitação sexual que surge no trauma da guerra, que tem a ver com o perigo (ou melhor, que confronta o perigo) pode ser satisfeita pelo reconhecimento do general da submissão, da obediência, da servidão do soldado.

Em Além do princípio do prazer, Freud afirma que a excitação sexual que surge no trauma pode ser ligada se houver uma ferida física. Freud aproxima a neurose de guerra à demência precoce e à melancolia. Há aproximação das neuroses narcisistas tanto no sofrimento subjetivo quanto no enfraquecimento e no transtorno das funções psíquicas. Além disso, elas se atenuam, todas as três, quando há um efetivo trauma físico, quando há uma ferida, uma doença. Por que isso ocorre? Porque os investimentos psíquicos se dirigem à ferida dolorida e desenvolvem um contrainvestimento para deter a dor. Este contrainvestimento, por sua vez, liga a excitação do terror, ou melhor, liga a excitação sexual provocada na situação de perigo (ou provocada pela violência mecânica). A ferida dolorida, portanto, possibilita uma certa organização psíquica, um trabalho de ligação, uma atividade do Eu que, em vez de permanecer passivo, toma a ferida como seu objeto de cuidado. Essa análise de Freud é importante porque mostra que a vivência de dor, a ferida dolorida, pode constituir o núcleo do processo de ligação. Não se trata apenas de se proteger de uma vivência de dor ou, quando isso não ocorre, proteger-se a posteriori (repetir para elaborar). A própria dor pode consistir no núcleo do processo de ligação, no núcleo do Eu. Os psicóticos (demência precoce e melancolia) e o neurótico traumático se aliviam com a ferida física certamente porque ela satisfaz algum impulso, o mesmo portanto também deve ocorrer com a submissão ao pai, ela também deve satisfazer algum impulso mais primário que o desejo de se submeter e de ser mulher para ele. Podemos aqui encontrar mais uma vez as tendências masoquistas do eu, seja na sede de submissão, e nos impulsos que sexualizam a servidão em vez de se opor a ela; seja na satisfação com a dor e nos impulsos que sexualizam a dor em vez de dela fugir.

É interessante que também na história filogenética a ferida física está relacionada com a demência precoce, com o narcisismo, no qual o Eu é tomado como objeto, e com a hipocondria. Na hipocondria também ocorre a volta do interesse e da libido para um órgão, geralmente substituto do sexual. A castração efetiva, realizada pelo pai primitivo, teria suscitado a disposição para a sexualização da dor (a hipocondria) e para a concentração de todo interesse e libido numa parte do próprio Eu, essa parte portanto 
tomando o lugar de objeto. A sexualização da dor por sua vez coincide com o desejo de submeter-se ao pai e de ser castrado (portanto, ferido) por ele. Assim, a ferida corresponde a ter sido ferido por alguém e neste sentido a um masoquismo relativo a um outro externo sádico. Na história filogenética, a ferida determinou a submissão ao pai e essa foi a condição para o surgimento da vida social ${ }^{8}$.

O fato do órgão dolorido poder ser o núcleo do processo de ligação, quer dizer, da constituição do Eu, mostra um outro lado do Eu, conhecido a partir do estudo das forças repressivas. Ele se constitui também a partir da dor, transformando a dor em prazer, cuidando do órgão, da ferida, possibilitando que a dor seja contornada e se transforme em prazer.

\section{Pulsão de MORTE}

Mas se as tendências masoquistas ainda se referem a uma ligação, ainda se trata da sexualidade, elas são a manifestação mais próxima de uma compulsão à repetição que se opõe ao processo de ligação. Elas seriam uma ligação a posteriori, que contornam e transformam em prazer a destruição da proteção (proteção proporcionada pela membrana protetora e pela energia ligada). Antes delas deve haver uma tendência mais primária, que se opõe efetivamente à proteção e à ligação, uma tendência para a dor (sem sexualizá-la), uma tendência a deixar-se ser invadido pelas altas quantidades do mundo externo. Freud então supõe uma tendência que, diferentemente dos caminhos facilitados do Projeto, não busca eliminar as quantidades de forma mais eficiente, ao contrário, se opõe a qualquer tentativa de proteção, de ligação e de eliminação, uma tendências a deixar-se ser invadido pelas altas quantidades destruidoras do mundo externo ${ }^{9}$. A fonte dessa tendência será a pulsão de morte, fundamentada biologicamente. Há tendências mortíferas, em todos os organismos, que têm de ser expelidas para que o organismo não morra. Elas são expelidas no contato com outro organismo (troca de

\footnotetext{
${ }^{8}$ Como tentei mostrar em Filogênese da metapsicologia freudiana, de acordo com Visão geral das neuroses de transferência, o desejo de submeter-se ao pai é fundamental para, depois do parricídio e da identificação com o pai por meio de sua devoração, o ódio voltar-se contra si mesmo, contra os próprios impulsos (masoquismo do eu correspondente ao sadismo da instância que depois será chamada de supereu).

${ }^{9}$ É verdade que a tendência à eliminação das quantidades, como Monzani mostrou, remete a uma tendência mortuária presente já no Projeto, "uma atração irresistível para o vazio e para a não excitação absoluta" (Monzani, 2014, p. 216). Mas isso, parece-me, ocorre em um organismo já constituído que, em vez de viver suas tensões, suas diferenças vitais, busca livrar-se delas. A eliminação parece-me sim uma manifestação da pulsão de morte, mas uma manifestação posterior à tendência de se deixar ser invadido pelas altas Qs e da sexualização da dor. Seria, no meu entender, como a pulsão de morte se manifesta na psicologia do indivíduo, na psicologia do pai da horda primitiva. 
água para os protozoários ou a copulação). Para que o organismo se constitua, tem de haver um objeto externo para o qual a pulsão de morte se dirija. Esta fundamentação biológica é traduzida na linguagem psicanalítica: "Não cabe supor que esse sadismo [pulsão sádica que visa ferir o objeto] é na verdade uma pulsão de morte que foi empurrada do Eu pela influência da libido narcísica, de modo que surge apenas em relação ao objeto?” (FREUD, 2010c [1920], p. 226). [...] “O masoquismo, a volta da pulsão contra o próprio Eu, seria então na realidade, um retorno a uma fase anterior dele mesmo [fase anterior do sadismo], uma regressão [...] o masoquismo pode também ser primário" (FREUD, 2010c [1920], p. 226/7).

Então, se Freud supõe, por um lado, um aparelho organizado contra perturbadoras forças externas, tanto arquitetonicamente, com suas barreiras protetoras, como também em seu funcionamento, por meio do processo de ligação, ele supõe, por outro lado, nesse aparelho, um movimento oposto, que tende a restaurar um estado anterior a essa organização, portanto, que não se opõe às forças externas perturbadoras. Existe uma pulsão de morte, uma pulsão contra a vida, contra a barreira de proteção e contra o estado de ligação, um impulso que tenta restaurar o inorgânico, portanto, destruindo o orgânico. Assim, quando o vivente surgiu, da matéria inanimada, lhe sobreveio uma tensão que tentou anular a si mesmo. Quando dominada pelo processo de proteção ou ligação, essa tendência se torna prazer na dor, no cuidado com o órgão dolorido e na repetição das vivências dolorosas (masoquismo). Quando o organismo se constitui surgem pulsões que, por um lado, defendem a conservação do organismo contra forças exteriores avassaladoras e, por outro lado, se satisfazem com a influência devastadora das forças externas que o ferem e o matam.

No capítulo V, Freud escreve: "surge então um paradoxo de que o organismo vivo se rebela fortemente contra influências (perigos) que poderiam ajudá-lo a alcançar sua meta de vida por um caminho curto" (FREUD, 2010c [1920], p. 206). Por que rebelar-se contra o perigo é um paradoxo, se toda a arquitetura e funcionamento do aparelho psíquico visa a proteção contra o perigo? Justamente porque existem pulsões que querem conduzir ao inanimado, que não se rebelam contra perigos, que não se rebelam contra influências externas devastadoras, que não se rebelam contra as vivências de desprazer (de dor) e contra os traumas físicos (a ferida e a castração). E essa parece ser, portanto, a formulação da pulsão de morte: uma tendência a se deixar ser invadido por estímulos externos perigosos e devastadores.

\section{PULSÃo DE VIDA}


Se Freud leva ao extremo as tendências ao inorgânico, à morte, à oposição contra toda proteção e ligação do organismo, tem de supor outra pulsão tão primária e independente como a de morte, que justifique a vida, a função de proteção, de ligação e de sexualização da tendência à destruição, cujo fundamento deve se apoiar em um argumento diferente do raciocínio biológico que fundamentou a pulsão de morte. A fundamentação será então no mito de Platão, do Banquete, no qual os seres duplos foram partidos em dois que, desde então, desejam se fundir. $\mathrm{O}$ mito é baseado em outro, dos Upanishads, que supõe que o Si-mesmo foi dividido em partes. Mito que possibilita a suposição de que a substância viva foi desmembrada em pequenas partículas que agora visam se reunir e que, diante dos estímulos perigosos para a vida, formam a camada cortical protetora, a multicelularidade, as células germinais e a tendência em reunir o orgânico em unidades cada vez maiores.

No final do capítulo V, Freud afirma que a tendência para reunir o orgânico em unidades cada vez maiores substitui a "pulsão de aperfeiçoamento":

o esforço de Eros para reunir o orgânico em unidades cada vez maiores provavelmente substitui a "pulsão de aperfeiçoamento" que não podemos admitir. Associados aos efeitos da repressão, ele pode explicar os fenômenos atribuídos à essa (FREUD, 2010c [1920], p. 210/1).

Antes dessa explicação, no entanto, Freud faz uma importante referência ao além do homem (Übermenschen, superhomem). Figura que, devemos lembrar, em Psicologia das massas e análise do Eu, Freud remeteu à psicologia do indivíduo, do pai primitivo, que, segundo Freud, Nietzsche esperava no futuro mas estava no passado, e que, em Filogênese da metapsicologia freudiana, relacionei com a psicologia dos fortes, nobres, primeiros conquistadores da Genealogia da moral (em oposição à psicologia dos fracos, da massa, dos filhos submissos e ressentidos da horda primitiva). Em Além do princípio do prazer, a referência ao além do homem, aparece assim:

Para muitos de nós pode ser difícil abandonar a crença de que no próprio homem há um impulso para a perfeição, que o levou a seu atual nível de realização intelectual e sublimação ética e do qual se esperaria que cuidasse de seu desenvolvimento rumo ao além do homem. [...] A evolução humana, até agora, não me parece necessitar de explicação diferente daquela dos animais, e o que observamos de incansável ímpeto rumo à perfeição, numa minoria de indivíduos, pode ser entendido como consequência da repressão das pulsões em que se baseia o que há de mais precioso na cultura humana. A pulsão reprimida jamais desiste de lutar 
por sua completa satisfação, que consistiria na repetição de uma vivência primária de satisfação; todas as formações substitutas e reativas, todas as sublimações, não bastam para suprimir sua contínua tensão, e da diferença entre o prazer de satisfação encontrado e $o$ exigido resulta o fator impulsor que não admite a permanência em nenhuma das situações produzidas, mas, nas palavras do poeta, "sempre impele, indomável para a frente" (Mefistófeles, no Fausto, I, Gabinete de estudos). O caminho para trás, para a completa satisfação, é em geral obstruído pelas resistências que mantêm as repressões, e assim não resta senão continuar pela direção de desenvolvimento ainda livre, embora sem perspectiva de encerrar o processo e poder alcançar a meta (FREUD, 2010c [1920] p. 209/10, grifo nosso). ${ }^{10}$

A repressão, agora, pode ser atribuída à própria pulsão de morte que luta com a pulsão de vida "desde os primórdios" e que não lhe dá descanso (e que será mais bem elaborada com o conceito de supereu). Mas a alusão ao além do homem parece aqui contrapor-se ao outro conceito também nietzschiano, encontrado em Assim falou Zaratustra, e também usado por Freud, em Além do princípio do prazer: o eterno retorno mesmo. Freud alude a ele quando descreve a compulsão à repetição que aparece no destino de algumas pessoas (cf., Freud 2010 [1920] p. 182), ideia fundamental para a formulação da pulsão de morte. Se deixarmos a crítica do além do homem de lado (supondo-a como uma necessidade de Freud de negar a influência de Nietzsche sobre seu pensamento) e pensarmos a pulsão ao aperfeiçoamento como autosuperação, podemos dizer que, ao relacionar o além do homem com a pulsão de vida e contrastá-los ao eterno retorno relacionado com a pulsão de morte, Freud entreviu um outro aspecto daquilo que ele chamou de a psicologia do pai primevo (que se contrapõe à psicologia do ressentido). O eterno retorno (a compulsão à repetição) necessariamente não precisa se expressar em submissão e ressentimento (como ocorre nas massas e na psicologia dos filhos). $\mathrm{O}$ além do homem que, diante das massas, da decadência e do ressentimento, se estabelece como forte e criador, pode também, diante do eterno retorno, querer exatamente a repetição, querer para trás, querer o que foi; ele pode, como Dionísio, buscar morrer do seu próprio modo, suportar artisticamente sua existência, dissipar as tensões e as diferenças vitais, vivendo-as. Mas esse é um tema para um outro artigo.

Também podemos pensar que se, para Freud, o masoquismo é o fundamento do processo cultural, ele pode ser mais intenso, como na psicologia das massas ressentidas, que não só intensificam a dor e a submissão como não suportam a existência e os

\footnotetext{
${ }^{10}$ Devemos aqui lembrar da importância da pulsão para a perfeição em Lamarck e, portanto, apontar como o projeto de Freud com Ferenczi de relacionar Lamarck e a psicanálise parece estar relacionado diretamente com as reflexões de Freud sobre Nietzsche. 
próprios impulsos agressivos e, por isso, criam valores opostos à existência e destroem acreditando construir, ou pode ser menos intenso, ele pode reverter-se em impulsos agressivos mais autênticos e em contornos do vazio; ou pode ainda propiciar uma existência que se suporta artisticamente. Mas esse também é assunto para ser desenvolvido posteriormente.

\section{CONSIDERAÇõES FINAIS}

Concluindo, podemos afirmar que a leitura de Além do princípio do prazer, tendo como base o Projeto de uma psicologia e Visão geral das neuroses de transferência, possibilitou-nos compreender a pulsão de morte como fundamento da disposição passivo-masoquista, disposição que é o fundamento dos laços sociais, já que esses se constituem não apenas pela pulsão de vida, que busca formar unidades cada vez mais extensas, mas também da submissão diante do outro, da culpa e do ódio contra si mesmo, contra as próprias pulsões, elementos fundamentais para a constituição do contrato social.

\section{REFERÊNCIAS}

CORRÊA, Fernanda S. Filogênese da metapsicologia freudiana. Campinas, S.P. Editora da Unicamp, 2015.

FREUD, Sigmund. (1985 [1915]) Neuroses de Transferência: Uma síntese (Manuscrito recém-descoberto). Versão bilíngue, trad. Abram Eksterman. Rio de Janeiro: Imago, 1987.

(1950 [1895]) Projeto de uma psicologia. Obras isoladas de Freud, trad. Osmyr Faria Gabbi Jr., Rio de Janeiro: Imago, 1995.

(1894) Rascunho G. In: Masson, J. M. A correspondência completa de Sigmund Freud para Wilhelm Fliess. Rio de Janeiro: Imago, 1986.

(1905) Três ensaios sobre a teoria da sexualidade. In: Freud, S. Obras completas, vol. 6, trad. Paulo César de Souza. São Paulo: Companhia das Letras, 2016.

(1911a) Observações psicanalíticas sobre um caso de paranoia (Dementia paranoides) relatado em autobiografia ('O caso Schreber'). In: Freud, S. Obras Completas, vol. 10, trad. Paulo César de Souza. São Paulo: Companhia das Letras, 2010a.

(1911b) Formulação sobre os dois princípios do funcionamento psíquico. In: Freud, S. Obras Completas, vol. 10, trad. Paulo César de Souza. São Paulo, Companhia 
das Letras, 2010a.

(1912-1913) Totem e tabu. In: Freud, S. Obras Completas, vol. 11, trad. Paulo César de Souza. São Paulo: Companhia das Letras, 2012.

(1914) Introdução ao narcisismo. In: Freud, S. Obras Completas, vol. 12, trad. Paulo César de Souza. São Paulo: Companhia das Letras, 2010 b.

(1915a) Os impulsos e seus destinos. In: Freud, S. Obras Completas, vol. 12, trad. Paulo César de Souza. São Paulo: Companhia das Letras, 2010 b.

(1917b [1915]) Luto e melancolia. In: Freud, S. Obras Completas, vol. 12, trad. Paulo César de Souza. São Paulo: Companhia das Letras, 2010 b.

(1918 [1914]) História de uma neurose infantil ('O homem dos lobos'). In: Freud, S. Obras Completas, vol. 14, trad. Paulo César de Souza. São Paulo: Companhia das Letras, 2010c.

(1921) 'Batem numa criança': contribuição ao conhecimento da gênese das perversões sexuais. In: Freud, S. Obras Completas, vol. 14, trad. Paulo César de Souza. São Paulo: Companhia das Letras, 2010c.

(1920) Além do princípio do prazer. In: Freud, S. Obras Completas, vol. 14, trad. Paulo César de Souza. São Paulo: Companhia das Letras, 2010c.

(1921) Psicologia das massas e análise do eu. In: Freud, S. Obras Completas, vol. 15, trad. Paulo César de Souza. São Paulo: Companhia das Letras, 2011.

(1985 [1915]) Übersicht der Übertragungsneurosen: Ein bisher unbekanntes Manuskript - Ediert Ilse Grubrich-Simitis. Frankfurt am Main: S.Fischer Verlag, 1985.

(1950 [1895]) Entwurf Einer Psychologie. In: Freud, S. Gesammelte Werke, Nachtragsband. Frankfurt am Main: Fischer Verlag, 1987.

(1905) Drei Abhandlung zur Sexualtheorie. In: Freud, S. Studienausgabe. Band V. Frankfurt am Main: Fischer Taschenbuch Verlag, 1982.

(1911a) Psychoanalytische Bemerkungen über einen autobiographisch beschriebenen Fall vn Paranoia (Dementia paranoides). In: Freud, S. Studienausgabe. Band VII. Frankfurt am Main: Fischer Taschenbuch Verlag, 1982.

(1911b) Formulierung über die zweit Prinzipien des psychischen Geschehens. In: Freud, S. Studienausgabe. Band III. Frankfurt am Main: Fischer Taschenbuch Verlag, 1982.

(1912-1913) Totem und Tabu. In: Freud, S. Studienausgabe. Band IX. Frankfurt am Main: Fischer Taschenbuch Verlag, 1982.

(1914) Zur Einführung des Narzißmus. In: Freud, S. Studienausgabe. Band III. Frankfurt am Main: Fischer Taschenbuch Verlag, 1982. 
(1918 [1914]) Aus der Geschichte einer infantilen Neurose. In: Freud, S. Studienausgabe. Band VIII. Frankfurt am Main: Fischer Taschenbuch Verlag, 1982.

(1920) Jenseits des Lustprinzips. In: Freud, S. Studienausgabe. Band III. Frankfurt am Main: Fischer Taschenbuch Verlag, 1982.

(1921) Massenpsychologie und Ich-Analyse. In: Freud, S. Studienausgabe. Band IX. Frankfurt am Main: Fischer Taschenbuch Verlag, 1982.

GIACOIA JR, Oswaldo. Além do princípio do prazer: Um dualismo incontornável (Para ler Freud). Rio de Janeiro: Civilização brasileira, 2008.

JONES, Ernest. Vida e obra de Sigmund Freud (organização e resumo Trilling e Marcus). Rio de Janeiro: Zahar editores, 1979.

MASSON, Jeffrey Moussaieff. A correspondência completa de Sigmund Freud para Wilhelm Fliess. Rio de Janeiro: Imago, 1986.

MONZANI, Luiz Roberto. Freud: o movimento de um pensamento. Campinas: Editora Unicamp, 1989.

MÜLLER-LAUTER, Wolfgang. Nietzsche: sua filosofia dos antagonismos e os antagonismos de sua filosofia. São Paulo: Editora Unifesp, 2009.

NIETZSCHE, Friedrich. (1884) Assim falou Zaratustra. Coleção Obras de Nietzsche, trad. e coord. Paulo César de Souza. São Paulo: Companhia da Letras, 2011.

(1887) Genealogia da moral. Coleção Obras de Nietzsche, trad. e coord. Paulo César de Souza. São Paulo: Companhia da Letras, 1998.

Recebido em: 31/08/2020

Aceito para publicação em: 15/09/2020 